\title{
Prospective analysis of the efficacy of beraprost sodium combined with alprostadil on diabetic nephropathy and influence on rennin-angiotensin system and TNF- $\alpha$
}

\author{
XINWEI XU ${ }^{1}$, XIAOJING PAN ${ }^{2}$ and SONG $\mathrm{LI}^{2}$ \\ Departments of ${ }^{1}$ Nephrology and ${ }^{2}$ Blood Purification, \\ Weifang People's Hospital, Weifang, Shandong 261041, P.R. China
}

Received June 13, 2019; Accepted October 8, 2019

DOI: $10.3892 /$ etm.2019.8265

\begin{abstract}
Efficacy of beraprost sodium (BPS) combined with alprostadil on diabetic nephropathy (DN) and its influence on renin angiotensin system (RAS) and TNF- $\alpha$ were investigated. One hundred and two patients with type 2 diabetic nephropathy admitted to Weifang People's Hospital from July 2017 to January 2019 were selected and divided into two groups according to the treatment plan. Fifty patients with alprostadil were the control group and 52 patients with alprostadil combined with BPS were the combined group. Related indexes of fasting blood glucose, hemorheology, coagulation function, renal function, urine routine, liver function, renin angiotensin system and changes of TNF- $\alpha$ (ELISA) were observed, and the occurrence of adverse reactions of patients were recorded. The fasting blood glucose of patients in the two groups after treatment was lower than that before treatment $(\mathrm{P}<0.05)$. After treatment, blood viscosity, plasma viscosity and erythrocyte deformation exponent of patients in the two groups decreased $(\mathrm{P}<0.05)$, and the combined group was lower than the control group $(\mathrm{P}<0.05)$. After treatment, the average volume of fibrinogen (FIB), D dimer and platelets of the patients in the two groups decreased $(\mathrm{P}<0.05)$, and the combined group was lower than the control group $(\mathrm{P}<0.05)$. After treatment, UACR, CysC, $\beta 2-M G$ and $\alpha 1-M G$ of patients decreased in the two groups $(\mathrm{P}<0.05)$, and the combined group was lower than the control group $(\mathrm{P}<0.05)$. After treatment, renin and angiotensin II of patients decreased in both groups $(\mathrm{P}<0.05)$. TNF- $\alpha$ of patients in both groups decreased after treatment $(\mathrm{P}<0.05)$, and the combined group was lower than the control group $(\mathrm{P}<0.05)$. In conclusion, compared with alprostadil, BPS combined with alprostadil can effectively improve hemody-
\end{abstract}

Correspondence to: Dr Song Li, Department of Blood Purification, Weifang People's Hospital, 151 Guangwen Street, Kuiwen, Weifang, Shandong 261041, P.R. China

E-mail: sxub48@163.com

Key words: beraprost sodium, alprostadil, diabetic nephropathy, hemorheology, renin angiotensin system, TNF- $\alpha$ namics, coagulation function and renal function of DN patients, and inhibit expression of RAS-related factors and TNF- $\alpha$, which is a more effective method for DN treatment.

\section{Introduction}

With the rising incidence rate of diabetes, the risk of morbidity and the occurrence of diabetes complications increases dramatically (1). Diabetic nephropathy (DN) is one of the serious microvascular complications of diabetes, accounting for approximately $40 \%$ of end-stage renal disease, second only to tubal nephritis $(2,3)$. At present, the commonly used treatment methods mainly include controlling blood sugar, maintaining blood pressure and inhibiting renin angiotensin system (RAS). Due to the complicated pathogenesis of DN, there is no clinical method to completely treat DN. Although the occurrence of DN can be delayed, its development still cannot be prevented or reversed (4). DN is an inflammatory disease, therefore anti-inflammation is one of the keys to control the disease. Inflammatory cytokines are closely related to the disease process of DN. Inhibition of TNF- $\alpha$ expressions has been proved to have protective effects on the kidneys $(5,6)$. Finding more effective drugs or treatments is a top priority.

Beraprost sodium (BPS) is an oral prostacyclin derivative, which has good antiplatelet aggregation, vasodilation and antioxidant activities. It can inhibit the proliferation of vascular smooth muscle cells and the production of inflammatory cytokines, increase blood flow, effectively improve microcirculation and increase erythrocyte deformation $(7,8)$. Some studies have shown that BPS can effectively repair renal microvasculature and reduce renal interstitial fibrosis, inhibit local RAS key factors, angiotensin II receptor 1, angiotensin converting enzyme, angiotensinogen, promote expression of angiotensin II receptor 2 , and delay the development of chronic renal failure $(9,10)$. Alprostadil can increase the intimal blood flow of body nerve cells, dilate blood vessels and reduce the resistance of peripheral blood vessels. Moreover, alprostadil can inhibit platelet aggregation, effectively improve renal blood flow and reduce proteinuria $(11,12)$. BPS and alprostadil have both been reported to treat $\mathrm{DN}(13,14)$, but there are few related studies on the combination of BPS and alprostadil, and its efficacy still needs further verification. 
Therefore, the aim of this study was to provide references for clinical treatment of DN by investigating the efficacy of BPS combined with alprostadil on DN and its influence on renin angiotensin system and TNF- $\alpha$.

\section{Patients and methods}

Study subjects. A total of 102 patients with type 2 diabetic kidney disease who were admitted to Weifang People's Hospital (Weifang, China) from July 2017 to January 2019, aged 40-60 years were studied. Based on whether alprostadil combined with BPS was the drug treatment, patients were divided into two groups. A total of 50 patients with alprostadil treatment were the control group and 52 patients with alprostadil combined with BPS were the combined group. Inclusion criteria: All the patients met the WHO 1999 diagnostic criteria for type 2 diabetic nephropathy (15) and were diagnosed as DN patients for the first time. The patients' urinary albumin/creatinine was $\geq 30 \mathrm{mg} / \mathrm{mmol}$ or $\leq 300 \mathrm{mg} / \mathrm{mmol}$, and the urea nitrogen and creatinine indicators were within the normal range. Relevant treatments were not performed before serum samples were obtained, and clinical data of patients were complete. Exclusion criteria: Patients with renal failure, kidney stones and a medical history of digestive system diseases in active phase, adrenocortical hyperfunction, abnormal liver and heart-lung functions; pregnant women or breast-feeding patients; patients with mental diseases or abnormal brain judgment.

This study was approved by the Medical Ethics Committee of Weifang People's Hospital. Patients who participated in this research had complete clinical data. The signed informed consents were obtained from the patients or the guardians.

Treatment methods. All patients had a low-salt and low-fat diet, and according to their own blood glucose levels and kidney damage, all patients were treated with conventional drugs: oral administration of gliguidone or subcutaneous injection of insulin; administration of $100 \mathrm{mg} /$ day aspirin (H31021877, Shanghai Baolong Pharmaceutical Co., Ltd.), $20 \mathrm{mg} /$ day simvastatin (H20030207, Jingxin Pharmaceutical Co., Ltd.). Patients in control group were treated with $10 \mu \mathrm{g}$ alprostadil $+50 \mathrm{ml}$ normal saline intravenous drip for the first 2 weeks, once a day, and the administration was stopped after 2 weeks. Only conventional treatments were performed for the second 2 weeks. Patients in combined group were treated with the same drugs as the control groups for two weeks, then the administration of alprostadil was stopped. Combined with the conventional treatment, BPS was administered orally, $40 \mu \mathrm{g} / \mathrm{time}$, twice a day.

Observation indicators. Related indexes of fasting blood glucose (blood glucose detector, Jinan Hanfang Medical Devices Co., Ltd.), hemorheology (automatic blood hemorheology analyzer, Jinan Gelite Technology Co., Ltd.), coagulation function (full automatic hemagglutination analyzer, Sysmex), renal function and $24 \mathrm{~h}$ urinary protein (Upro) (full automatic biochemical analyzer, Beckman Olympus), renin angiotensin system (full automatic chemiluminescence instrument, Wuhan Mingde Biotechnology Co., Ltd.), and changes of TNF- $\alpha$ (ELISA) were observed before and after treatment, and the occurrence of adverse reactions of patients in the two groups were recorded. TNF- $\alpha$ and ELISA kit were purchased from Diken (Shanghai) Trading Co., Ltd., article number: BE45471.

Statistical analysis. SPSS 19.0 (SPSS, Inc.) was used. The measurement data were expressed by $\mathrm{n}(\%)$, and the comparison of rates between the two groups was performed by $\chi^{2}$ test. Enumeration data were expressed by mean \pm SD. Comparison between the two groups was conducted by independentsamples t-test, and the comparison before and after treatment was conducted by paired-samples t-test. $\mathrm{P}<0.05$ was considered as statistically significant.

\section{Results}

General information. There were 50 patients in the control group, including 35 males (70.00\%), 15 females (30\%), aged $52.38 \pm 9.36$ years, and 52 patients in combined group, including 34 males $(65.38 \%), 18$ females $(34.62 \%)$, aged $53.15 \pm 10.14$ years. There was no significant difference in sex ratio and age of patients between the two groups $(P>0.05)$, and there was no significant difference in BMI and other data of patients between the two groups $(\mathrm{P}>0.05)$ (Table I).

Analysis of complications of patients after treatment in the two groups. There were no significant adverse reactions in the groups, but mild adverse reactions still occurred. In the control group, there were 2 cases of mild vascular pain, 3 cases of mild nausea, 4 cases of diarrhea, and 5 cases of mild headache. The total adverse rate was $28.00 \%$. In the combined group, there were 1 case of mild vascular pain, 1 case of mild nausea, 2 cases of diarrhea, and 2 cases of mild headache. The total adverse rate was $11.54 \%$. There was a significant difference in the total adverse rate between the two groups $(\mathrm{P}<0.05)$ (Table II).

Changes of blood glucose after treatment of patients in the two groups. Blood glucose levels of patients in control group before and after treatment were $7.02 \pm 0.42 \mathrm{mmol} / \mathrm{l}$ and $6.03 \pm 1.22 \mathrm{mmol} / \mathrm{l}$, respectively, while blood glucose levels of patients in combined group before and after treatment were $6.99 \pm 0.46 \mathrm{mmol} / 1$ and $6.09 \pm 1.13 \mathrm{mmol} / 1$, respectively. There was no statistical difference in fasting blood glucose of patients between the two groups before and after treatment ( $P>0.05$ ), but the fasting blood glucose of patients in the two groups after treatment was lower than that before treatment $(\mathrm{P}<0.05)$ (Fig. 1).

Hemorheological changes of patients in the two groups after treatment. Before treatment, there was no difference in blood viscosity, plasma viscosity and erythrocyte deformation exponent of patients between the two groups $(\mathrm{P}>0.05)$. After treatment, blood viscosity, plasma viscosity and erythrocyte deformation exponent of patients between the two groups decreased $(\mathrm{P}<0.05)$, and the combined group was lower than the control group $(\mathrm{P}<0.05)$ (Table III).

Changes of coagulation function of patients after treatment in the two groups. There was no difference in the average 
Table I. Comparison of clinical data of patients between the two groups [n (\%)] (mean \pm SD).

\begin{tabular}{|c|c|c|c|c|}
\hline Factors & Control group $(\mathrm{n}=50)$ & Joint group $(\mathrm{n}=52)$ & $\chi^{2 / t}$ value & P-value \\
\hline Sex & & & 0.248 & 0.618 \\
\hline Male & $35(70.00)$ & $34(65.38)$ & & \\
\hline Female & $15(30.00)$ & $18(34.62)$ & & \\
\hline Age (years) & $52.38 \pm 9.36$ & $53.15 \pm 10.14$ & 0.398 & 0.914 \\
\hline $\operatorname{BMI}\left(\mathrm{kg} / \mathrm{m}^{2}\right)$ & $23.82 \pm 3.41$ & $24.16 \pm 4.14$ & 0.452 & 0.652 \\
\hline Course of diabetes (years) & $10.45 \pm 5.62$ & $10.29 \pm 5.81$ & 0.141 & 0.888 \\
\hline Retinopathy & & & 1.178 & 0.758 \\
\hline No & $30(60.00)$ & $29(55.77)$ & & \\
\hline Simple type & $17(34.00)$ & $17(32.69)$ & & \\
\hline Maculopathy & $1(2.00)$ & $3(5.77)$ & & \\
\hline Proliferation & $2(4.0)$ & $3(5.77)$ & & \\
\hline History of cardiovascular disease & & & 0.837 & 0.975 \\
\hline Myocardial infarction & $12(24.00)$ & $15(28.85)$ & & \\
\hline Coronary artery disease & $3(6.00)$ & $2(3.85)$ & & \\
\hline Peripheral arterial disease & $3(6.00)$ & $3(5.77)$ & & \\
\hline Venous insufficiency & $4(8.00)$ & $3(5.77)$ & & \\
\hline Stroke or transient ischemic stroke & $2(4.00)$ & $3(5.77)$ & & \\
\hline Unknown & $26(52.00)$ & $26(50.00)$ & & \\
\hline Glycosylated hemoglobin (\%) & $7.06 \pm 1.58$ & $7.17 \pm 1.65$ & 0.344 & 0.732 \\
\hline Smoking & & & 1.912 & 0.167 \\
\hline Yes & $22(44.00)$ & $30(57.69)$ & & \\
\hline No & $28(56.00)$ & $22(42.31)$ & & \\
\hline
\end{tabular}

Table II. Complications of patients after treatment in the two groups.

\begin{tabular}{|c|c|c|c|c|}
\hline Complications & Control group $(\mathrm{n}=50)$ & Combined group $(\mathrm{n}=52)$ & t value & P-value \\
\hline \multicolumn{5}{|l|}{ Vascular pain } \\
\hline Mild pain & $2(4.00)$ & $1(1.92)$ & 0.364 & 0.618 \\
\hline Severe pain & 0 & 0 & & \\
\hline \multicolumn{5}{|l|}{ Nausea } \\
\hline Mild nausea & $3(6.00)$ & $1(1.92)$ & 1.124 & 0.358 \\
\hline Severe nausea & 0 & 0 & & \\
\hline \multicolumn{5}{|l|}{ Diarrhea } \\
\hline Mild diarrhea & $4(8.00)$ & $2(3.85)$ & 0.794 & 0.432 \\
\hline Severe diarrhea & 0 & 0 & & \\
\hline \multicolumn{5}{|l|}{ Headache } \\
\hline Mild headache & $5(10.00)$ & $2(3.85)$ & 1.510 & 0.265 \\
\hline Severe headache & 0 & 0 & & \\
\hline Total adverse rate & $14(28.00)$ & $6(11.54)$ & 4.382 & 0.047 \\
\hline
\end{tabular}

volume of plasma fibrinogen (FIB), D dimer and platelet of patients between the two groups before treatment $(\mathrm{P}>0.05)$. After treatment, the average volume of FIB, D dimer and platelet of patients in the two groups decreased $(\mathrm{P}<0.05)$, and the combined group was lower than the control group $(\mathrm{P}<0.05)$ (Table IV).
Changes of renal function of patients after treatment in the two groups. There was no difference in UACR, CysC, $\beta 2-\mathrm{MG}$ and $\alpha 1-\mathrm{MG}$ of patients between the two groups before treatment (P>0.05). After treatment, UACR, CysC, $\beta 2-\mathrm{MG}$ and $\alpha 1-\mathrm{MG}$ of patients decreased in the two groups $(\mathrm{P}<0.05)$, and the combined group was lower than the control group $(\mathrm{P}<0.05)$ (Table $\mathrm{V})$. 
Table III. Hemorheological changes of patients after treatment in the two groups.

\begin{tabular}{|c|c|c|c|c|}
\hline Hemorheological changes & Control group $(n=50)$ & Joint group $(\mathrm{n}=52)$ & t value & P-value \\
\hline \multicolumn{5}{|l|}{ Blood viscosity (m/pas) } \\
\hline Before treatment & $21.03 \pm 2.21$ & $20.96 \pm 2.18$ & 0.616 & 0.842 \\
\hline After treatment & $13.52 \pm 2.65^{\mathrm{a}}$ & $11.67 \pm 2.53^{\mathrm{a}}$ & 3.607 & 0.001 \\
\hline \multicolumn{5}{|l|}{ Plasma viscosity (m/pas) } \\
\hline Before treatment & $3.75 \pm 0.52$ & $3.71 \pm 0.54$ & 0.381 & 0.704 \\
\hline After treatment & $2.11 \pm 0.71^{\mathrm{a}}$ & $1.82 \pm 0.47^{\mathrm{a}}$ & 2.441 & 0.016 \\
\hline \multicolumn{5}{|c|}{ Erythrocyte deformation exponent } \\
\hline Before treatment & $8.68 \pm 1.47$ & $8.66 \pm 1.53$ & 0.067 & 0.947 \\
\hline After treatment & $6.08 \pm 2.12^{\mathrm{a}}$ & $4.05 \pm 2.24^{\mathrm{a}}$ & 4.697 & $<0.001$ \\
\hline
\end{tabular}

${ }^{\mathrm{a}}<0.05$, compared with the same group before treatment.

Table IV. Changes of coagulation function of patients after treatment in the two groups.

\begin{tabular}{|c|c|c|c|c|}
\hline Coagulation function changes & Control group $(n=50)$ & Joint group $(\mathrm{n}=52)$ & t value & P-value \\
\hline \multicolumn{5}{|l|}{$\mathrm{FIB}(\mathrm{g} / \mathrm{l})$} \\
\hline Before treatment & $5.12 \pm 0.82$ & $5.15 \pm 0.71$ & 0.198 & 0.844 \\
\hline After treatment & $4.88 \pm 0.61^{\mathrm{a}}$ & $4.54 \pm 0.67^{\mathrm{a}}$ & 2.677 & 0.009 \\
\hline \multicolumn{5}{|l|}{$\mathrm{D}$ dimer $(\mu \mathrm{g} / \mathrm{l})$} \\
\hline Before treatment & $1.86 \pm 0.64$ & $1.84 \pm 0.82$ & 0.137 & 0.891 \\
\hline After treatment & $1.91 \pm 0.64^{\mathrm{a}}$ & $1.37 \pm 0.77^{\mathrm{a}}$ & 3.844 & $<0.001$ \\
\hline \multicolumn{5}{|l|}{ Average platelet volume (fl) } \\
\hline Before treatment & $12.24 \pm 1.95$ & $12.25 \pm 1.88$ & 0.026 & 0.979 \\
\hline After treatment & $10.93 \pm 1.92^{\mathrm{a}}$ & $9.72 \pm 1.12^{\mathrm{a}}$ & 3.906 & $<0.001$ \\
\hline
\end{tabular}

${ }^{a} \mathrm{P}<0.05$, compared with the same group before treatment. FIB, fibrinogen.

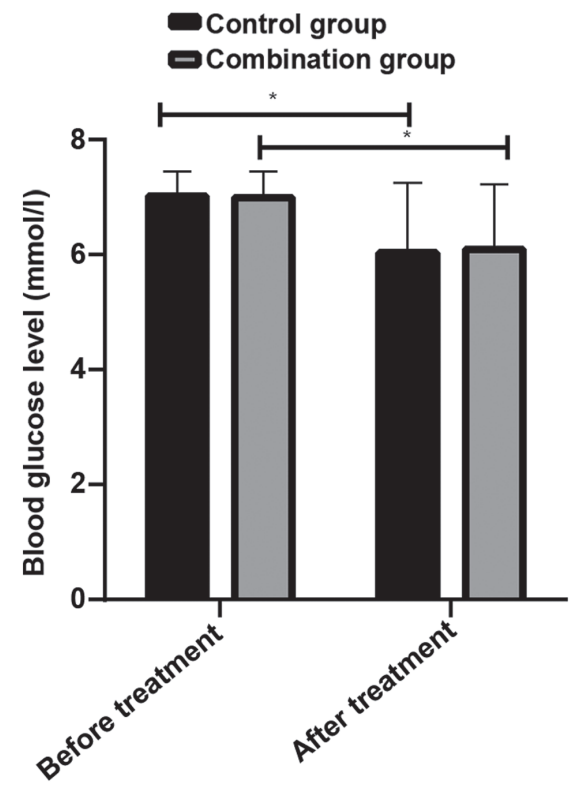

Figure 1. Changes of blood glucose of patients after treatment in the two groups. There was no significant difference in fasting blood glucose of patients between the two groups before and after treatment $(\mathrm{P}>0.05)$, but fasting blood glucose of patients in the two groups after treatment was lower than that before treatment $(\mathrm{P}<0.05)$. ${ }^{*} \mathrm{P}<0.05$.

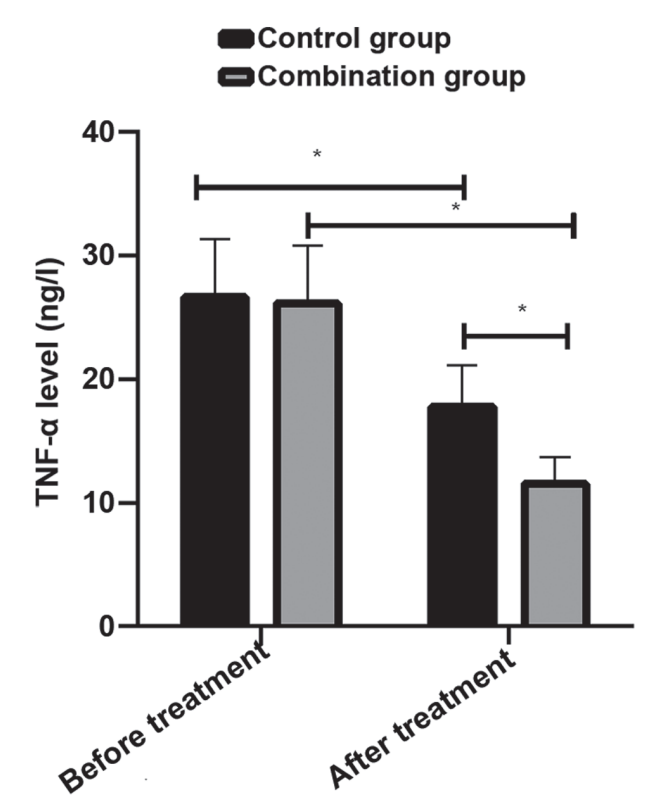

Figure 2. Changes of TNF- $\alpha$ of patients after treatment in the two groups. There was no difference in TNF- $\alpha$ of patients between the two groups before treatment $(\mathrm{P}>0.05)$. TNF- $\alpha$ of patients in both groups decreased after treatment $(\mathrm{P}<0.05)$, and the combined group was lower than the control group $(\mathrm{P}<0.05) .{ }^{*} \mathrm{P}<0.05$. 
Table V. Changes of renal function of patients after treatment in the two groups.

\begin{tabular}{|c|c|c|c|c|}
\hline Renal function changes & Control group $(n=50)$ & Joint group $(\mathrm{n}=52)$ & t value & P-value \\
\hline \multicolumn{5}{|l|}{$\mathrm{UACR}(\mu \mathrm{mol} / \mathrm{l})$} \\
\hline Before treatment & $31.11 \pm 4.13$ & $29.96 \pm 3.37$ & 1.544 & 0.126 \\
\hline After treatment & $19.73 \pm 2.42^{\mathrm{a}}$ & $12.12 \pm 1.88^{\mathrm{a}}$ & 17.775 & $<0.001$ \\
\hline \multicolumn{5}{|l|}{ CysC (mg/l) } \\
\hline Before treatment & $2.21 \pm 0.34$ & $2.27 \pm 0.37$ & 0.852 & 0.396 \\
\hline After treatment & $1.53 \pm 0.21^{\mathrm{a}}$ & $0.93 \pm 0.22^{\mathrm{a}}$ & 14.079 & $<0.001$ \\
\hline \multicolumn{5}{|l|}{$\beta 2-\mathrm{MG}(\mathrm{mg} / \mathrm{l})$} \\
\hline Before treatment & $3.92 \pm 0.61$ & $3.93 \pm 0.51$ & 0.090 & 0.929 \\
\hline After treatment & $2.84 \pm 0.47^{\mathrm{a}}$ & $1.93 \pm 0.36^{\mathrm{a}}$ & 11.004 & $<0.001$ \\
\hline \multicolumn{5}{|l|}{$\alpha 1-\mathrm{MG}(\mathrm{mg} / \mathrm{l})$} \\
\hline Before treatment & $16.23 \pm 2.14$ & $16.37 \pm 2.27$ & 0.320 & 0.750 \\
\hline After treatment & $12.74 \pm 1.82^{\mathrm{a}}$ & $8.43 \pm 1.18^{\mathrm{a}}$ & 14.246 & $<0.001$ \\
\hline \multicolumn{5}{|l|}{ Upro (mg/day) } \\
\hline Before treatment & $132.52 \pm 8.97$ & $130.64 \pm 7.61$ & 1.143 & 0.256 \\
\hline After treatment & $62.14 \pm 6.39$ & $58.68 \pm 5.91$ & 2.841 & 0.006 \\
\hline
\end{tabular}

${ }^{a} \mathrm{P}<0.05$, compared with the same group before treatment. UACR, urine protein creatinine ratio; CysC, plasma cystatin C; $\beta 2-\mathrm{MG}, \beta 2 \mathrm{micro}-$ globulin; $\alpha 1-\mathrm{MG}$, urine $\alpha 1$ microglobulin.

Table VI. Changes of related indexes of renin angiotensin system of patients after treatment in the two groups.

\begin{tabular}{|c|c|c|c|c|}
\hline Related index changes & Control group $(n=50)$ & Joint group $(\mathrm{n}=52)$ & $\mathrm{t}$ value & P-value \\
\hline \multicolumn{5}{|l|}{$\operatorname{Renin}(\mathrm{pg} / \mathrm{ml})$} \\
\hline Before treatment & $21.15 \pm 4.26$ & $21.24 \pm 4.33$ & 0.106 & 0.916 \\
\hline After treatment & $17.26 \pm 5.13^{\mathrm{a}}$ & $13.41 \pm 3.79^{\mathrm{a}}$ & 4.323 & $<0.001$ \\
\hline \multicolumn{5}{|l|}{ Angiotensin II (pg/ml) } \\
\hline Before treatment & $261.42 \pm 53.88$ & $275.73 \pm 54.61$ & 1.332 & 0.186 \\
\hline After treatment & $217.79 \pm 58.68^{\mathrm{a}}$ & $157.27 \pm 40.79^{\mathrm{a}}$ & 6.068 & $<0.001$ \\
\hline \multicolumn{5}{|l|}{$\mathrm{ACE}(\mathrm{U} / \mathrm{l})$} \\
\hline Before treatment & $62.25 \pm 6.71$ & $63.94 \pm 7.58$ & 1.191 & 0.237 \\
\hline After treatment & $45.62 \pm 5.41$ & $42.87 \pm 4.73$ & 2.736 & 0.007 \\
\hline
\end{tabular}

${ }^{\mathrm{a}} \mathrm{P}<0.05$, compared with the same group before treatment. ACE, angiotensin converting enzyme.

Changes of related indexes of renin angiotensin system of patients after treatment in the two groups. Before treatment, there was no difference in renin and angiotensin II of patients between the two groups $(\mathrm{P}>0.05)$. After treatment, renin and angiotensin II of patients decreased in both groups $(\mathrm{P}<0.05)$, and the combined group was lower than the control group $(\mathrm{P}<0.05)$ (Table VI).

Changes of TNF- $\alpha$ after treatment in the two groups. Levels of TNF- $\alpha$ before and after treatment of patients in control group were $26.63 \pm 4.73 \mathrm{ng} / \mathrm{l}$ and $17.74 \pm 3.35 \mathrm{ng} / \mathrm{l}$, respectively, while levels of TNF- $\alpha$ before and after treatment of patients in combined group were $26.14 \pm 4.68 \mathrm{ng} / 1$ and $11.54 \pm 2.17 \mathrm{ng} / \mathrm{l}$, respectively. There was no difference in $\mathrm{TNF}-\alpha$ of patients between the two groups before treatment $(\mathrm{P}>0.05)$. Levels of
TNF- $\alpha$ of patients in the two groups decreased after treatment $(\mathrm{P}<0.05)$, and levels in combined group were lower than those in control group $(\mathrm{P}<0.05)$ (Fig. 2).

\section{Discussion}

The morbidity of diabetes is expected to increase to $7.7 \%$ in the world by 2030 (16). About one third of diabetic patients will be affected by DN. DN has become the main cause of end-stage renal disease in developed countries, with extremely high morbidity and mortality among diabetic patients $(17,18)$. At present, there is no cure for DN. It is necessary to find the best treatment scheme to delay the development of early DN. This study analyzed therapeutic effects of BPS combined with alprostadil in DN and its influences on renin angiotensin 
system and $\mathrm{TNF}-\alpha$, providing theoretical reference for clinical treatment.

BPS and alprostadil have both been reported for the treatment of DN. BPS is reported to be used in combination with RAS inhibitor to effectively prevent the progress of DN (19). Alprostadil can improve renal blood supply of DN patients, effectively delay the occurrence of fibrosis and protect renal function (20), but reports of combined application of the two in DN are few. Mathiesen et al (21) reported that BPS combined with alprostadil can protect renal function of DN patients, reduce proteinuria, improve glomerular filtration function and microcirculation disturbance, and inhibit platelet activation. BPS combined with alprostadil in the treatment of chronic renal failure has also been reported indicating that this treatment method can improve glomerular filtration rate, reduce urinary albumin excretion rate, slow down the increase of serum creatinine, reduce levels of FIB and D-dimer, thus delaying the progress of chronic renal failure caused by chronic glomerulonephritis, and with good safety (22). Results of the present study show that BPS combined with alprostadil can more effectively inhibit platelet and repair glomerular filtration, thereby improving hemodynamics, coagulation and renal function in patients with $\mathrm{DN}$, which are similar to the previously reported results $(21,22)$, and effects of combination and alprostadil alone on blood glucose are similar. At present, there is no study confirming that BPS or alprostadil can affect glucose metabolism in human body. Our study found no adverse reaction of patients in the two groups, which may be related to the duration of the treatment. Based on the above results, BPS combined with alprostadil has better efficacy on $\mathrm{DN}$, and will not increase the occurrence of adverse reactions in the short-term.

RAS exists in the circulatory system and is a humoral regulation system composed of hormones and enzymes, mainly including renin and angiotensin. It is of great significance to maintain the balance of body blood pressure, water, electrolyte and the stability of internal environment $(23,24)$. Our results show that BPS combined with alprostadil has another advantage in that it can effectively inhibit RAS, which is of great significance for maintaining the blood pressure of patients. In 1979, alprostadil was found to inhibit renin-angiotensin-aldosterone system (25). In subsequent studies, BPS derivative of alprostadil was also found to inhibit expression of RAS-related factors in mice, thus delaying the development of chronic renal failure (8), but influences of alprostadil on RAS are still uncertain.

Changes of TNF- $\alpha$ after treatment were analyzed. TNF- $\alpha$ changes glomerular hemodynamics and promotes the increase of vascular endothelial permeability. It can also promote infiltration of inflammatory cells, new formation of extracellular matrix, production of reactive oxygen species and blood flow disorders. Moreover, overexpression levels of TNF- $\alpha$ are closely related to the occurrence of proteinuria $(26,27)$. Collectively, the evidence suggests that TNF- $\alpha$ plays an important role in the pathogenesis of DN. It is also suggested that improving TNF- $\alpha$ level is important for treating DN. Our results show that BPS combined with alprostadil can reduce TNF- $\alpha$ level in patients' peripheral blood more effectively. In other disease-related studies, alprostadil has been shown to reduce TNF- $\alpha$ level in patients' serum and urinary protein is also reduced. Previous studies $(28,29)$ have shown that BPS and alprostadil can reduce the level of TNF- $\alpha$ and achieve protection for the human body. In blood glucose metabolism, insulin activates glucose transporter 4 (GLUT4) translocation to the cell membrane to reduce blood glucose levels (30), while AKT phosphorylation promotes the translocation of GLUT4 and down-regulates TNF- $\alpha$ (31). Prostaglandins promote AKT phosphorylation (32), while BPS promotes AKT expression (10). Therefore, BPS combined with proproterol in the treatment of renal injury can control blood glucose levels by activating AKT and inhibit TNF- $\alpha$-induced apoptosis and autophagy.

However, because this study is a prospective analysis, there will inevitably be some selectivity bias and Hawthorne effect. Thus, further study is required. A multi-center clinical randomized controlled study will be conducted in the future. The analysis on safety still needs to be verified, but we will continue to track patients and record their future changes.

Compared with alprostadil therapy, BPS combined with alprostadil can more effectively improve hemodynamics, coagulation function and renal function of DN patients, and inhibit expression of RAS related factors and TNF- $\alpha$, which is a more effective method to treat DN.

\section{Acknowledgements}

Not applicable.

\section{Funding}

No funding was received.

\section{Availability of data and materials}

The datasets used and/or analyzed during the present study are available from the corresponding author on reasonable request.

\section{Authors' contributions}

$\mathrm{XX}$ wrote the manuscript, analyzed and interpreted the patient general data. XP performed chemiluminescence and ELISA. SL was responsible for the analysis of observation indicators. All the authors read and approved the final manuscript.

\section{Ethics approval and consent to participate}

This study was approved by the Medical Ethics Committee of Weifang People's Hospital (Weifang, China). Patients who participated in this research had complete clinical data. The signed informed consents were obtained from the patients or the guardians.

\section{Patient consent for publication}

Not applicable.

\section{Competing interests}

The authors declare that they have no competing interests. 


\section{References}

1. Mayer-Davis EJ, Lawrence JM, Dabelea D, Divers J, Isom S, Dolan L, Imperatore G, Linder B, Marcovina S, Pettitt DJ, et al; SEARCH for Diabetes in Youth Study: Incidence trends of type 1 and type 2 diabetes among youths, 2002-2012. N Engl J Med 376: 1419-1429, 2017.

2. John S: Complication in diabetic nephropathy. Diabetes Metab Syndr 10: 247-249, 2016

3. Keri KC, Samji NS and Blumenthal S: Diabetic nephropathy: Newer therapeutic perspectives. J Community Hosp Intern Med Perspect 8: 200-207, 2018.

4. Magee C, Grieve DJ, Watson CJ and Brazil DP: Diabetic nephropathy: A tangled web to unweave. Cardiovasc Drugs Ther 31: 579-592, 2017.

5. Donate-Correa J, Martín-Núñez E, Muros-de-Fuentes M, MoraFernández C and Navarro-González JF: Inflammatory cytokines in diabetic nephropathy. J Diabetes Res 2015: 948417, 2015.

6. Yeo ES, Hwang JY, Park JE, Choi YJ, Huh KB and Kim WY: Tumor necrosis factor (TNF-alpha) and C-reactive protein (CRP) are positively associated with the risk of chronic kidney disease in patients with type 2 diabetes. Yonsei Med J 51: 519-525, 2010

7. Chen S, Xie S, He W, Wei D, Li S and Chen W: Beneficial effect of beraprost sodium plus aspirin in the treatment of acute ischemic stroke. Med Sci Monit 23: 4401-4407, 2017.

8. Tanaka S, Akaike T, Wu J, Fang J, Sawa T, Ogawa M, Beppu T and Maeda $\mathrm{H}$ : Modulation of tumor-selective vascular blood flow and extravasation by the stable prostaglandin 12 analogue beraprost sodium. J Drug Target 11: 45-52, 2003.

9. Li S, Wang Y, Chen L, Wang Z, Liu G, Zuo B, Liu C and Sun D: Beraprost sodium mitigates renal interstitial fibrosis through repairing renal microvessels. J Mol Med (Berl) 97: 777-791, 2019.

10. Wang XF, Zhang BH, Lu XQ and Wang P: Beraprost sodium, a stable analogue of PGI2, inhibits the renin-angiotensin system in the renal tissues of rats with chronic renal failure. Kidney Blood Press Res 43: 1231-1244, 2018.

11. Wei W, An XR, Jin SJ, Li XX and Xu M: Inhibition of insulin resistance by PGE1 via autophagy-dependent FGF21 pathway in diabetic nephropathy. Sci Rep 8: 9, 2018.

12. Zhang JZ, Kang XJ, Gao Y, Zheng YY, Wu TT, Li L, Liu F, Yang YN, Li XM, Ma YT, et al: Efficacy of alprostadil for preventing of contrast-induced nephropathy: A meta-analysis. Sci Rep 7: 1045, 2017

13. Goya K, Otsuki M, Xu X and Kasayama S: Effects of the prostaglandin I2 analogue, beraprost sodium, on vascular cell adhesion molecule-1 expression in human vascular endothelial cells and circulating vascular cell adhesion molecule-1 level in patients with type 2 diabetes mellitus. Metabolism 52: 192-198, 2003.

14. Qin L, Qin W, Wang J and Lin L: Combined treatment of diabetic nephropathy with alprostadil and calcium dobesilate. Exp Ther Med 14: 5012-5016, 2017.

15. Gabir MM, Hanson RL, Dabelea D, Imperatore G, Roumain J, Bennett PH and Knowler WC: Plasma glucose and prediction of microvascular disease and mortality: Evaluation of 1997 American Diabetes Association and 1999 World Health Organization criteria for diagnosis of diabetes. Diabetes Care 23 $1113-1118,2000$

16. Shaw JE, Sicree RA and Zimmet PZ: Global estimates of the prevalence of diabetes for 2010 and 2030. Diabetes Res Clin Pract 87: 4-14, 2010.

17. Tanabe K, Maeshima Y, Sato Y and Wada J: Antiangiogenic therapy for diabetic nephropathy. BioMed Res Int 2017: 5724069 , 2017.
18. Atkins RC: The epidemiology of chronic kidney disease. Kidney Int Suppl 94: S14-S18, 2005.

19. Shima A, Miyamoto M, Kubota Y, Takagi G and Shimizu W Beraprost sodium protects against diabetic nephropathy in patients with arteriosclerosis obliterans: A prospective, randomized, open-label study. J Nippon Med Sch 82: 84-91, 2015.

20. Luo C,Li T, Zhang C, Chen Q, LiZ, Liu J and Wang Y: Therapeutic effect of alprostadil in diabetic nephropathy: Possible roles of angiopoietin-2 and IL-18. Cell Physiol Biochem 34: 916-928, 2014.

21. Mathiesen ER, Hommel E, Olsen UB and Parving HH: Elevated urinary prostaglandin excretion and the effect of indomethacin on renal function in incipient diabetic nephropathy. Diabet Med 5: 145-149, 1988

22. Chen Y, Wan JX, Jiang DW, Fu BB, Cui J and Li GF: Clinical efficacy and safety of sequential treatment with alprostadil and beraprost sodium for chronic renal failure induced by chronic glomerulonephritis. Nan Fang Yi Ke Da Xue Xue Bao 33: 1521-1524, 2013 (In Chinese).

23. Santos RA, Ferreira AJ, Verano-Braga T and Bader M: Angiotensin-converting enzyme 2, angiotensin-(1-7) and Mas: New players of the renin-angiotensin system. J Endocrinol 216: R1-R17, 2013.

24. Raebel MA: Hyperkalemia associated with use of angiotensinconverting enzyme inhibitors and angiotensin receptor blockers. Cardiovasc Ther 30: e156-e166, 2012.

25. Miyamori I, FitzGerald GA, Brown MJ and Lewis PJ: Prostacyclin stimulates the renin angiotensin aldosterone system in man. J Clin Endocrinol Metab 49: 943-944, 1979.

26. Navarro-González JF and Mora-Fernández C: The role of inflammatory cytokines in diabetic nephropathy. J Am Soc Nephrol 19: 433-442, 2008

27. Navarro-González JF, Jarque A, Muros M, Mora C and García J: Tumor necrosis factor-alpha as a therapeutic target for diabetic nephropathy. Cytokine Growth Factor Rev 20: 165-173, 2009.

28. Liu CP and Yu ZJ: Study on L-ornithine-L-aspartate in the treatment of acute-on-chronic liver failure. Zhonghua Gan Zang Bing Za Zhi 19: 63-64, 2011 (In Chinese).

29. Deng J, Feng J, Liu T, Lu X, Wang W, Liu N, Lv Y, Liu Q, Guo $\mathrm{C}$ and Zhou Y: Beraprost sodium preconditioning prevents inflammation, apoptosis, and autophagy during hepatic ischemiareperfusion injury in mice via the P38 and JNK pathways. Drug Des Devel Ther 12: 4067-4082, 2018.

30. Ho Y: Glucose metabolism and diabetes. In: Patient-Specific Controller for an Implantable Artificial Pancreas. Springer, Singapore, pp11-17, 2019.

31. Nitulescu GM, Van De Venter M, Nitulescu G, Ungurianu A, Juzenas P, Peng Q, Olaru OT, Grădinaru D, Tsatsakis A, Tsoukalas $\mathrm{D}$, et al: The Akt pathway in oncology therapy and beyond (Review). Int J Oncol 53: 2319-2331, 2018.

32. Takenaga M, Ishihara T, Niimi J, Hamaguchi A, Asano T, Tsuchiya R, Ohta Y, Mizushima T and Yudoh K: Nano PGE1 enhances phosphorylation of ERK1/2 and Akt to promote recovery from motor dysfunction and muscle atrophy induced by sciatic nerve injury. Preprints 2019. https://www.preprints. org/manuscript/201901.0250/v1.

This work is licensed under a Creative Commons Attribution-NonCommercial-NoDerivatives 4.0 International (CC BY-NC-ND 4.0) License. 